\title{
ESCALA DE MENSURAÇÃO SUBJETIVA: estudo com foco na percepção dos materiais em cadeiras de jantar
}

\author{
Maria Regina Álvares Dias \\ Escola de Design - Universidade do Estado de Minas Gerais - UEMG \\ regina.alvares@gmail.com \\ Gilberto Almeida Jr. \\ Escola de Design - Universidade do Estado de Minas Gerais - UEMG \\ gajunior@gmail.com
}

Resumo: Este artigo apresenta um método de avaliação de produtos em relação à percepção de seus materiais pelos usuários, a partir de estudos realizados com cadeiras de jantar. O método de estudo é composto de diferentes testes e um deles será apresentado nesse artigo mostrando a avaliação de diferentes atributos associados a materiais de quatro diferentes famílias - metálicos, cerâmicos, poliméricos e naturais utilizados na fabricação de cadeiras para mesa de jantar. $O$ estudo é parte de um trabalho desenvolvido como pesquisa de mestrado e seus resultados mostram que o produto incorpora parte das propriedades de seus materiais e interferem consequentemente, nos mecanismos de percepção do usuário, refletindo no julgamento das cadeiras, mesmo que essas apresentem modelo semelhante. $O$ método pode ainda ser aplicado em outras tipologias de produtos, juntamente com diferentes ferramentas do design.

Palavras-chave: Design, Materiais, Percepção, Mobiliário

\begin{abstract}
This paper presents a method of product evaluation in relation to the perception of their material by users from studies with dining chairs. The method of study is composed of different tests and one of them will be presented in this paper showing the evaluation of different attributes associated with four different families of materials - metals, ceramics, polymers and natural - used in the manufacture of chairs for the dining table. The study is part of a work as master research and their results show that the product incorporates some properties of its material and consequently interfere in the user's perception mechanisms, reflecting the judgment of seats, even those presenting similar model. The method can also be applied to other types of products, along with different design tools.
\end{abstract}

Keywords: Design, Materials, Perception, Furniture 


\section{INTRODUÇÃO}

O foco do presente estudo está na relação entre os materiais empregados para a fabricação de cadeiras domésticas para mesa de jantar e sua influência nos aspectos de preferência do usuário. O estudo é mais amplo em outros aspectos e propõe um método composto por escalas de mensuração de questões subjetivas, referentes à preferência do usuário em relação ao material aplicado no produto (Almeida Jr, 2013).

O método em si apresentava diferentes etapas de avaliação dos materiais: percepção de texturas de material polimérico, identificação dos materiais, adequação do material para aplicação no produto e por último, conheceu-se a percepção dos atributos associados a quatro tipos de materiais, aplicados em um mesmo modelo de cadeira para mesa de jantar através de análise semântica e emitindo sua preferência em relação aos modelos apresentados na pesquisa.

Do ponto de vista do design, o produto é composto a partir de vários elementos, como forma, escala, volume, cor, material, textura, brilho, som, cheiro e outros que, de maneira indivisíveis, conformam o artefato final. Um dos elementos mais importantes é o material, que "permite a interface imediata entre os artefatos e o homem" (Manzini, 1993). Os materiais desempenham papel essencial no processo de concepção do produto: eles podem definir seu leque de funções, a durabilidade, os custos e sua aparência final. Da mesma forma, a experiência dos usuários tem papel importante nesse processo, uma vez que, ao interagirem com o produto, estabelecem relações sensoriais - táteis, visuais, auditivas, olfativas ou gustativas - que podem ser determinantes em sua concepção. Nesse sentido, o material da cadeira, bem como as características de sua superfície e sua conformação são elementos preponderantes na percepção de questões subjetivas ligadas ao bem-estar dos usuários.

Nessa perspectiva, o estudo experimental realizado com usuários para avaliar distintos materiais e cadeiras de jantar de diferentes materiais serviu para validar 0 método proposto por Almeida Jr (2013) "Avaliação dos aspectos subjetivos relacionados aos materiais: proposta de método de mensuração aplicado ao setor moveleiro". Considera-se que as avaliações subjetivas resultantes da pesquisa podem ser revertidas em informações objetivas, como, por exemplo, na definição das características do produto, na especificação técnica dos materiais, na definição de texturas e acabamentos, bem como em inúmeras possibilidades aplicativas.

\section{CADEIRAS E MATERIAIS}

As cadeiras são os objetos mais explorados pelos designers e arquitetos em seus projetos, sendo difícil identificar algum desses profissionais que não tenha projetado um exemplar. A diversidade de formas, cores, acabamentos e materiais empregados, representam bem a infinidade de possibilidades para sua construção. Os materiais utilizados na fabricação das cadeiras são os mais diversos - dos mais rústicos e tradicionais como a madeira maciça e fibras naturais, até os materiais processados através de grande tecnologia como polímeros e fibras de alta tecnologia que imprimem características particulares a cada objeto.

Ao longo da história foi atribuído a este produto simbolismo de posição social e status, sendo considerado um dos objetos mais importantes do mobiliário. As cadeiras conhecidas, datadas como mais antigas, foram as egípcias, que demonstravam grande riqueza e esplendor, facilmente percebidos pela utilização de materiais nobres na sua construção. Eram feitas de ébano, marfim, madeira dourada e cobertas com metais 
preciosos (GALI, 1988).

Atualmente as cadeiras e poltronas são fabricadas de inúmeros materiais e processos de fabricação, os quais influenciam na sua forma e significado. Abreu et al (2001) relatam que a indústria moveleira utiliza tanto materiais de natureza sintética quanto artificial, como os polímeros reforçados com fibras de vidro ou na forma de laminados plásticos para acabamentos em chapas de madeira.

São inúmeros os processos existentes e variadas as formas de se trabalhar com os incontáveis materiais, que atualmente ultrapassam 100 mil tipos diferentes. 0 uso dos materiais não se limita, pelo contrário, à medida que novos materiais são desenvolvidos e apresentados aos profissionais, um campo enorme de atuação do profissional de design se amplia.

\section{O MÉTODO}

A seleção do material é complexa e não se baseia apenas em exigências funcionais, na tecnologia de fabricação, sustentabilidade, economia, mas, igualmente, em seus valores estéticos, nas propriedades sensoriais, nos aspectos ergonômicos, em seus significados culturais e simbólicos.

Compreender como as pessoas respondem às propriedades sensoriais dos materiais, bem como saber quais são as reações afetivas e emocionais diante destes, ajuda os designers e engenheiros a selecioná-los, levando-se em conta a capacidade de proporcionar uma experiência positiva ao usuário, que em consequência, aumenta o valor percebido do produto.

O estudo objetivou estudar a percepção de materiais poliméricos, vitrocerâmicos, naturais e metálicos, empregados em quatro cadeiras. 0 teste de percepção foi aplicado com participantes voluntários. A amostra total foi de 30 indivíduos, sendo 20 homens e 10 mulheres. Como os testes propuseram diferentes tipos de análises, o perfil do usuário pôde ter caráter bastante abrangente. Preferiu-se os participantes que apresentaram maior grau de escolaridade, sem se restringir qualquer participação.

A montagem dos testes e seus momentos de avaliação considerou que os atributos estéticos do material têm relação direta com a impressão estética que sentimos sobre um objeto por meio dos sentidos, equivale ao prazer fisiológico (Jordan, 2002) e ao nível visceral do design, Norman (2005).

Os atributos práticos do material se relacionam diretamente ao uso, manuseio e experiência dos usuários com os objetos, resultando no prazer e efetividade, equivalem ao prazer psicológico (Jordan, 2002), o qual tem relação com as reações cognitivas, mentais e emocionais dos indivíduos e ao design comportamental de Norman (2005). Os atributos simbólicos dos materiais têm relação com os aspectos de estima, psíquicos e sociais, e correspondem ao prazer social e ideológico propostos por Jordan (2002) e ao design reflexivo definido por Norman (2005).

O método é composto por três testes, sendo que os dois primeiros tratam das questões relacionadas aos materiais com possível aplicação em cadeiras e o terceiro (FIG. 1) avalia o produto construído com diferentes materiais.

Qualquer um dos três testes pode ser aplicado isoladamente, dependendo do que se pretende analisar. Todos os registros foram feitos pelo avaliador dos testes, garantindo que todos os campos fossem devidamente preenchidos, no tempo adequado permitindo que o teste fosse conduzido de forma confortável e garantindo 
liberdade de interação dos avaliados com os materiais. Apenas a etapa que consistia da autoavaliação emocional foi preenchida pelo próprio usuário.

\begin{tabular}{|l|l|l|l|}
\hline Teste 3 & Momento 1 e 2: & $\begin{array}{l}\text { Objetivo: } \\
\text { Avaliar a preferência pelas } \\
\text { cadeiras e a percepção de } \\
\text { diferentes atributos } \\
\text { associados a quatro } \\
\text { materiais escolhidos para a } \\
\text { fabricação de um modelo } \\
\text { de cadeira para mesa de } \\
\text { jantar. Outro propósito é a } \\
\text { avaliação emocional dos } \\
\text { modelos apresentados. }\end{array}$ & $\begin{array}{l}\text { Tipo de avaliaano } \\
\text { escolher entre 4 cadeiras a } \\
\text { mais e menos adequada de } \\
\text { acordo com seu material. } \\
\text { Cadeiras apresentadas na } \\
\text { forma de imagens coloridas } \\
\text { com suas respectivas } \\
\text { amostras de materiais: } \\
\text { metal, acrílico, madeira e } \\
\text { vidro. }\end{array}$ \\
Momento 3: & $\begin{array}{l}\text { Obs.: Não foi testada a } \\
\text { cadeira de vidro pela } \\
\text { dificuldade apresentada em } \\
\text { construir protótipo com o } \\
\text { material. }\end{array}$ & $\begin{array}{l}\text { Momento 3: avaliar, testar } \\
\text { e escolher a cadeira mais e } \\
\text { menos adequada entre 3 } \\
\text { cadeiras apresentadas na } \\
\text { forma de protótipos nos } \\
\text { materiais: metal, acrílico e } \\
\text { madeira. }\end{array}$ \\
\hline
\end{tabular}

Figura 1 - Detalhamento do teste 3 e seus respectivos momentos de avaliação.

Fonte: Elaborado pelo autor, com base na pesquisa realizada.

Esse artigo discute a terceira etapa do método, avaliando a percepção de diferentes atributos, associados a quatro materiais escolhidos para a fabricação de um mesmo modelo de cadeira para mesa de jantar. Além da avaliação semântica, o usuário emitiu sua preferência em relação aos modelos apresentados na pesquisa, através de visualização de imagens representativas dos produtos e experimentação dos protótipos.

\section{TESTE 3: PERCEPÇÃO DOS MATERIAIS DAS CADEIRAS, PREFERÊNCIA, EXPERIMENTAÇÃO E ESCOLHA DO PRODUTO}

A avaliação de materiais quando aplicados em produtos exige mais esforço do aparelho cognitivo do indivíduo se comparado à análise de amostras de materiais sem o contexto do produto. Segundo Rouvray (2006), a forma de avaliar e interagir com o produto produz níveis de percepção distintos. Existem diferentes formas de se avaliar a resposta emocional da interação humano-produto, desde a mais simples e menos custosa, através de fotografias, a intermediária, através de prototipagem virtual, até a interação completa com produtos reais inseridos no ambiente de uso indicado. Comprovando os estudos do autor, o nível de interação ou informação sobre o que é avaliado, interfere na percepção dos indivíduos e nas suas escolhas. Existe diferença no resultado quando só se pode ver, quando se pode tocar e mais ainda quando a interação é possível.

Com a intenção de conhecer quais os atributos possuem maior e menor importância em relação a uma cadeira de jantar, e como a decisão de compra do 
produto é influenciada por eles, os usuários indicaram subjetivamente o grau de importância de vários critérios. A FIG. 2 mostra a ocorrência e distribuição das atribuições de valor para cada item. A análise dos dados mostrou que os critérios de design, conforto, material e acabamento, e experimentação e teste da cadeira antes da compra foram indicados como de maior importância. Vale ressaltar que o critério design abrange questões relacionadas ao estilo do produto, inovação, qualidade de projeto, entre outras. Os atributos peso, moda e tendências, aspectos de status, luxo e marca e aspectos ligados à sustentabilidade, receberam notas variadas com grande percentual de notas de menor ou pouca importância. Os atributos ergonomia, preço, facilidade de limpeza e segurança de uso, apresentaram notas intermediárias com valores indicando serem de maior importância.

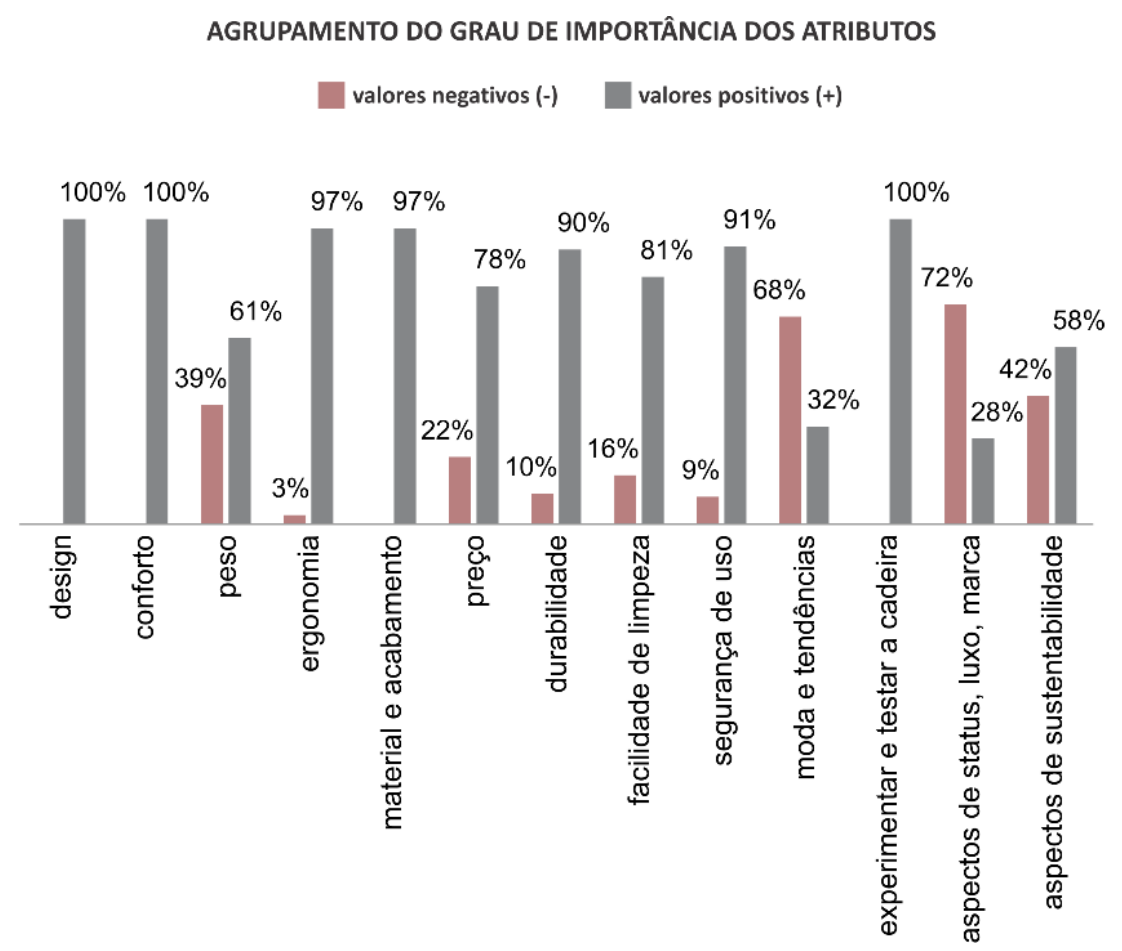

Figura 2 - Detalhamento dos três testes aplicados e seus respectivos momentos de avaliação.

Fonte: Elaborado pelo autor, com base na pesquisa realizada.

O teste 3 deu-se em três momentos de avaliação. No primeiro foi realizada a avaliação visual dos quatro modelos de cadeiras construídas em quatro famílias de materiais como já mencionado, escolhendo a cadeira preferida e a que não escolheria considerando o material. Juntamente com a imagem de cada cadeira foi disponibilizada uma amostra do material correspondente para que houvesse interação.

\subsection{Primeiro Momento de Avaliação}

Iniciou-se o teste 3 com a seguinte instrução: "simulando o momento de aquisição, selecione a cadeira de sua preferência considerando os materiais, independente da ergonomia, cores e preço." Para sua realização, era importante olhar as imagens das cadeiras e tocar nas amostras dos materiais localizados próximos à imagem correspondente. Na finalização, os usuários deveriam indicar uma segunda cadeira como sendo a que não escolheriam. A figura 3 indica os índices de preferência 
e rejeição para cada uma das quatro cadeiras.

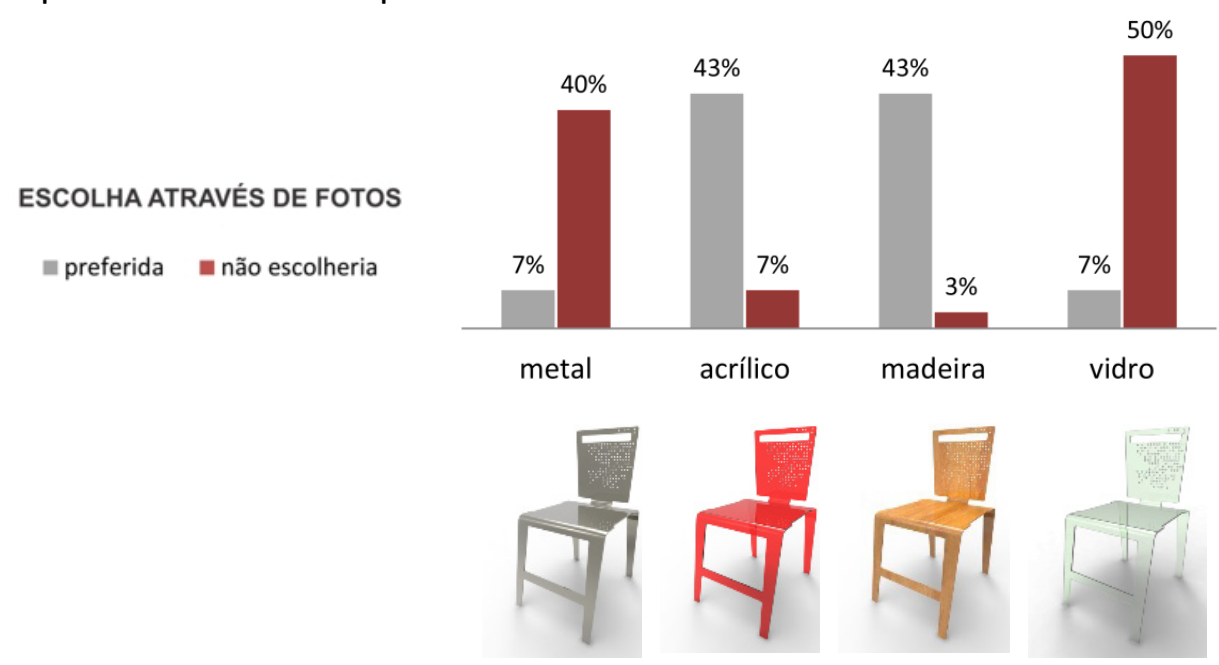

Figura 3 - Percentual de escolha das cadeiras através das fotos e contato com o material. Fonte: Elaborado pelo autor, com base na pesquisa realizada.

Observa-se que tanto a cadeira de acrílico quanto a de madeira, tiveram cada uma $43 \%$ das escolhas dos usuários. A cadeira que não seria escolhida indicando 50 de rejeição seria a de vidro. Outro modelo que teve alto índice de recusa foi a de metal, recebendo $40 \%$ dos votos.

\subsection{Segundo Momento de Avaliação}

No segundo momento do teste foi apresentado um grupo de descritores e era avaliado o grau de importância de cada um deles. Foram listados 12 pares de atributos com escala de valores de 6 graus (muito, médio e pouco) para cada atributo (FIG. 4).

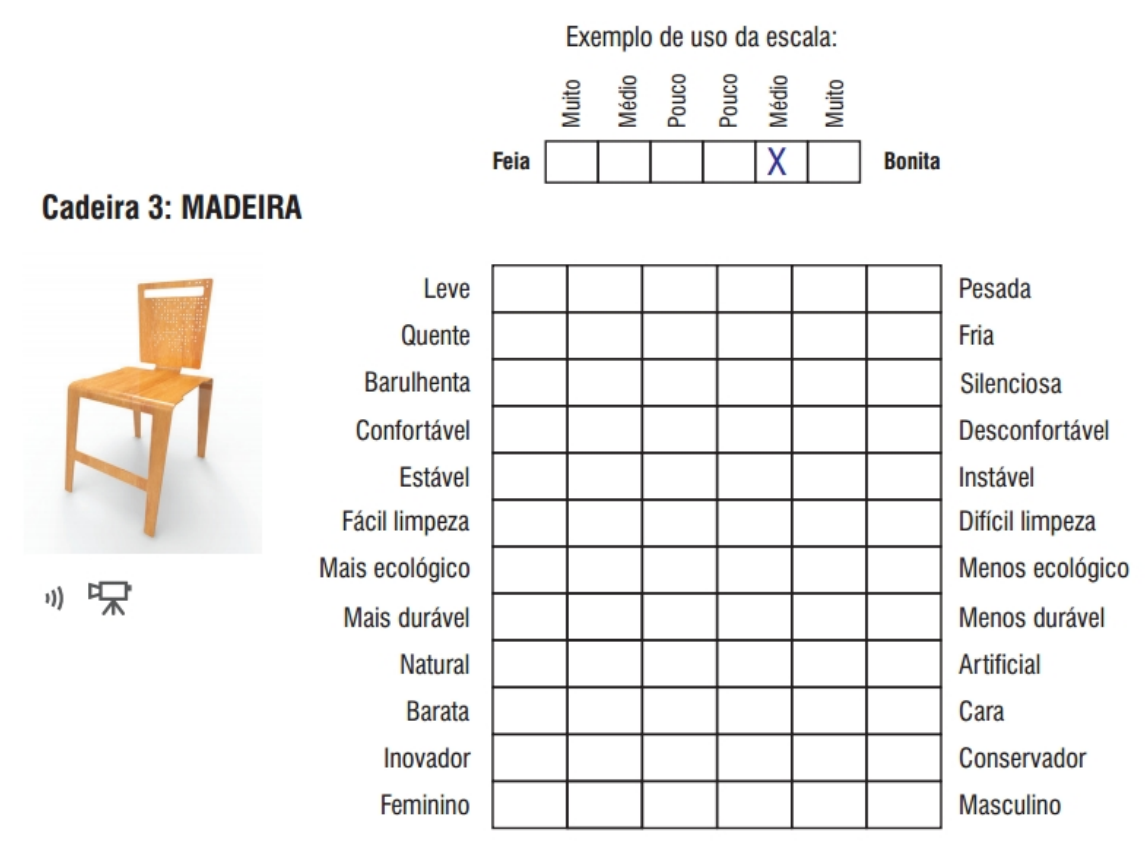

Figura 4 - Diferencial semântico com grupo de descritores para avaliar o grau de importância de cada atributo.

Fonte: Elaborado pelo autor, com base na pesquisa realizada. 
Os atributos correspondiam a: som, peso, temperatura, durabilidade, estabilidade, conforto, limpabilidade, inovação, ecologia, personalidade, preço, naturalidade do material. Foi dada a instrução para "assinalar o grau de importância dos atributos para cada uma das cadeiras" apresentadas através de imagem que indicava o material aplicado. Como o procedimento teve registro de voz e vídeo, o formulário possuía ícones específico abaixo das imagens das cadeiras para que o avaliador indicasse se usuário apresentou algum movimento ou disse algo relevante para análise posterior.

Os dados obtidos através dessa avaliação passaram por tratamento estatístico para análise de variância pela técnica ANOVA. Este método considera conjuntamente as avaliações de todos os avaliados e assume que todos apresentam o mesmo comportamento, considerando suas individualidades. É possível identificar ainda a média para cada atributo sensorial avaliado (Minim, 2010).

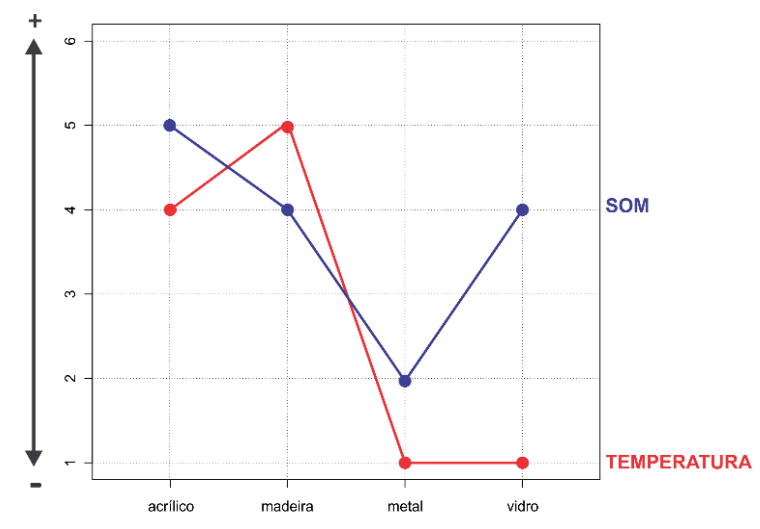

A cadeira de metal foi considerada a mais silenciosa e a de acrílico a mais barulhenta. A cadeira de madeira e a de vidro apresentaram mesma classificação, indicando que são pouco barulhentas.

$\mathrm{O}$ atributo temperatura revelou que a cadeira de metal e a de vidro foram ambas consideradas muito frias, enquanto a de madeira foi avaliada como médio quente, e a de acrílico a mais quente de todas.

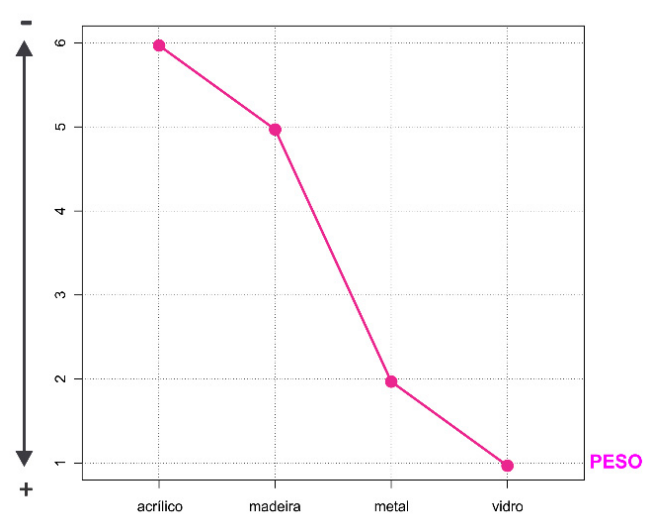

A cadeira de vidro foi a mais pesada na opinião dos usuários do teste, seguida pela cadeira de metal. De acordo com a escala utilizada, a cadeira de madeira foi considerada médio leve e a de acrílico a mais leve entre todas as quatro testadas.

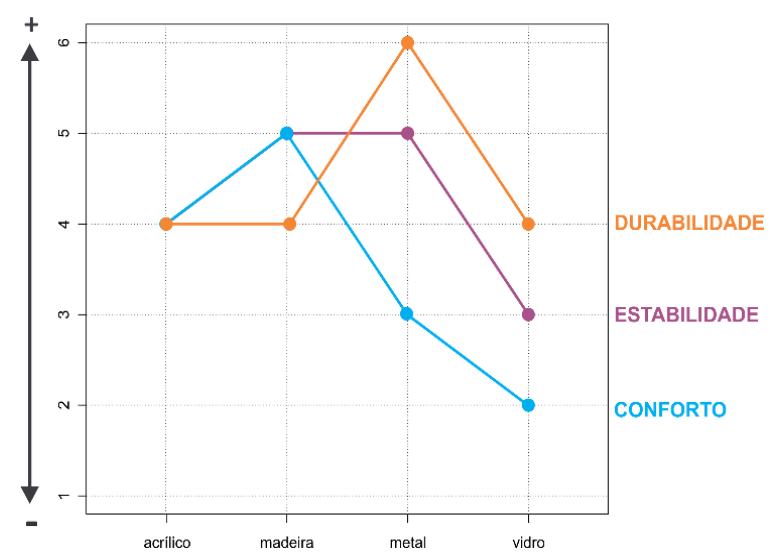

A cadeira de metal foi considerada a mais durável. Todas as demais indicaram possuir valores positivos de durabilidade.

Quanto a estabilidade, as cadeiras de madeira e de metal, são as mais estáveis. A cadeira de vidro indicou ser a mais instável.

Em relação ao conforto, a cadeira de madeira foi indicada como a mais confortável e a de vidro a mais desconfortável. 

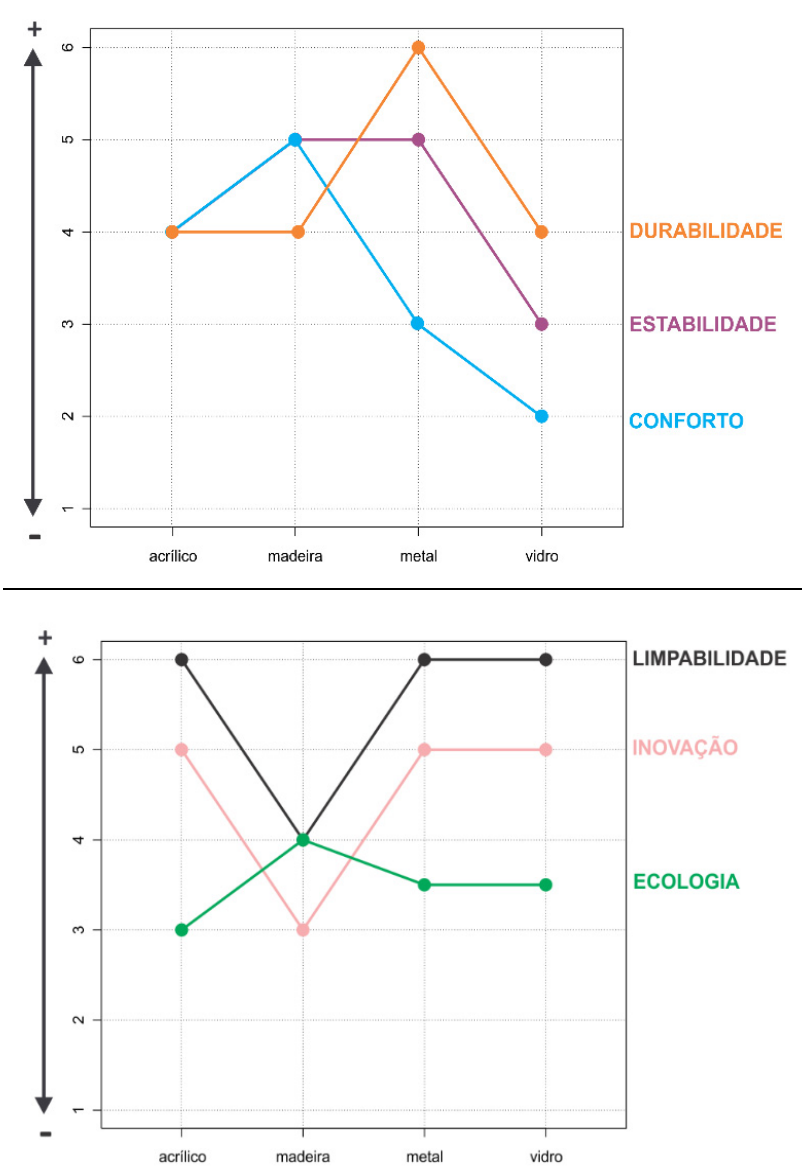

A cadeira de metal foi considerada a mais durável. Todas as demais indicaram possuir valores positivos de durabilidade.

Quanto a estabilidade, as cadeiras de madeira e de metal, são as mais estáveis. A cadeira de vidro indicou ser a mais instável.

Em relação ao conforto, a cadeira de madeira foi indicada como a mais confortável e a de vidro a mais desconfortável.

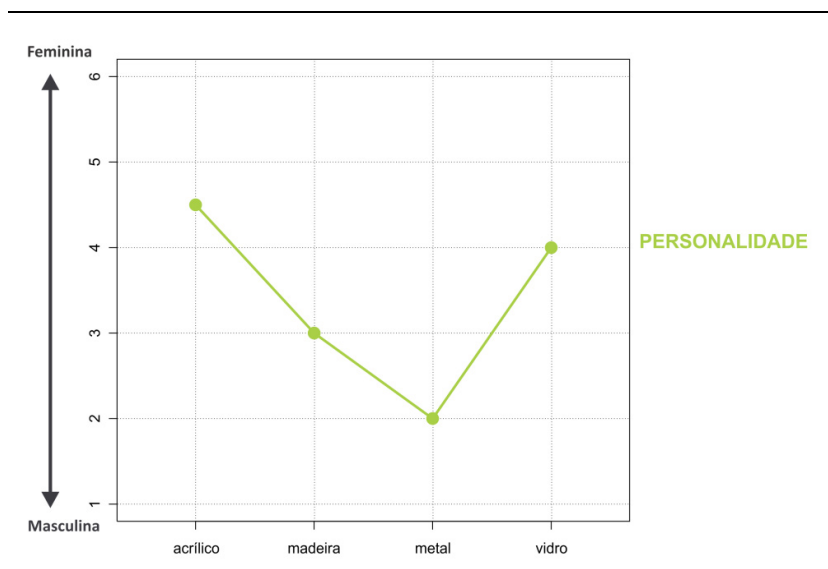

Quanto a limpabilidade apenas a cadeiras de madeira foi considerada pouco fácil de limpar, todas as outras foram consideradas muito fáceis de serem limpas.

O critério inovação apresenta todas as cadeiras como mais inovadoras, apenas a de madeira indicada como mais conservadora entre as quatro.

No aspecto ecologia, a cadeira de acrílico foi considerada a menos ecológica e a de madeira a mais ecológica. As cadeira de metal e vidro atingiram classificação neutra.

Materiais, processos, forma, peso e cor, contribuem para a criação de personalidade. Nessa avaliação foi medido o caráter masculino e feminino do produto.

Portanto, em relação à personalidade, a cadeira de acrílico e a de vidro apresentaram caráter feminino. Já a de metal e a de madeira apresentaram caráter masculino. A cadeira de acrílico foi a mais feminina e a de metal a mais masculina.

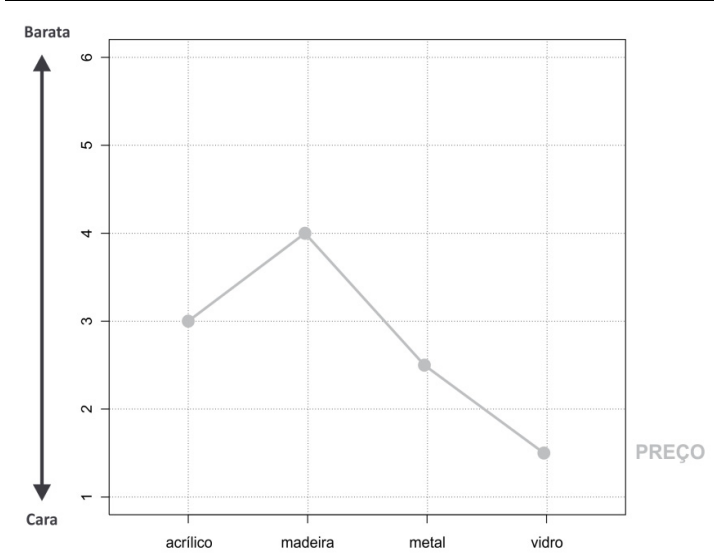

Em relação ao preço, a cadeira de madeira foi considerada a mais barata de todas e a de vidro a mais cara. A cadeira de metal foi considerada médio cara e a de acrílico pouco cara. 


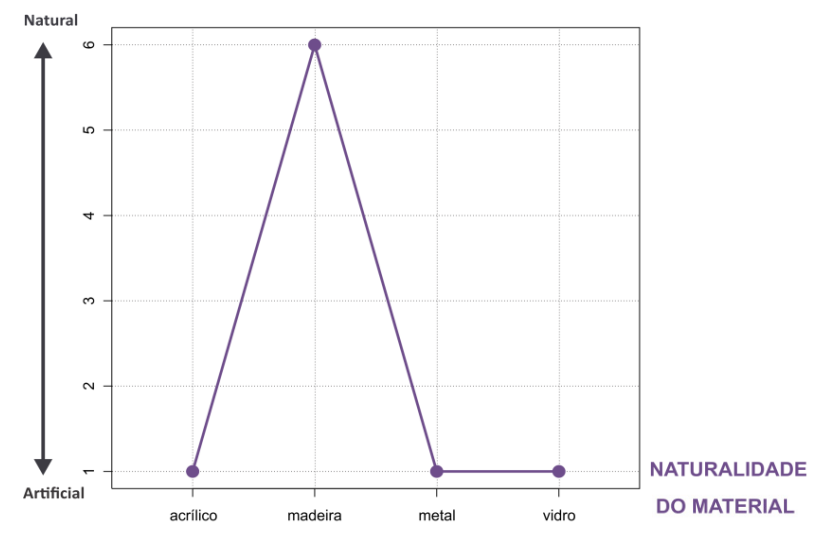

Quanto à naturalidade do material, a cadeira de madeira foi considerada como sendo de origem natural e tanto as cadeira de metal, acrílico e vidro foram consideradas artificiais.

Figura 5 - Resultado da ANOVA para cada a dos 12 pares de atributos avaliados.

Fonte: Elaborado pelo autor, com base na pesquisa realizada.

Ainda no segundo momento, o usuário respondia uma escala para autoavaliação emocional, apresentando quais sensações eram atribuídas a cada uma das quatro cadeiras. Aplicou-se um método utilizado por Desmet (2004) e Dias (2009), por ter sido empregado em estudos anteriores que comprovaram sua eficiência.

Define-se como uma escala circular com 7 emoções positivas e 7 negativas, sendo as positivas localizadas no lado direito e as negativas no lado esquerdo, com intensidade variando de muito forte, médio ou fraco, com a parte externa do círculo indicando mais intensidade e a interna menos intensidade.
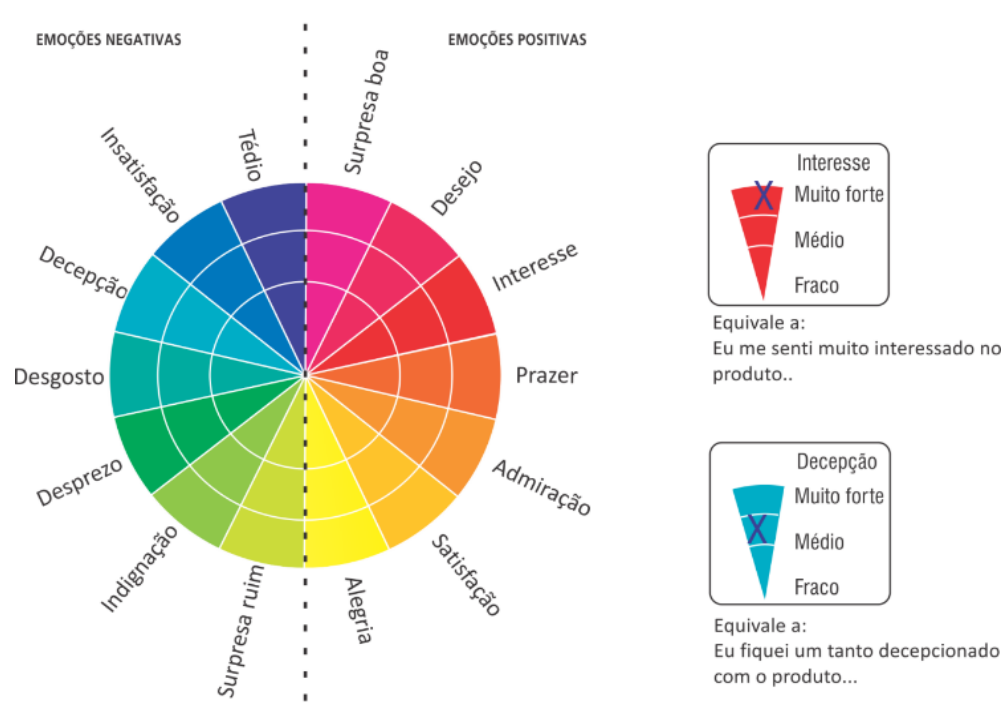

Figura 6 - Escala utilizada para autoavaliação emocional utilizada no estudo.

Fonte: Dias (2009).

O resultado da análise de autoavaliação emocional das cadeiras foi organizado de acordo com os atributos avaliados. A porcentagem do total de escolhas visto na figura 7 representa a amostra de 30 usuários. 


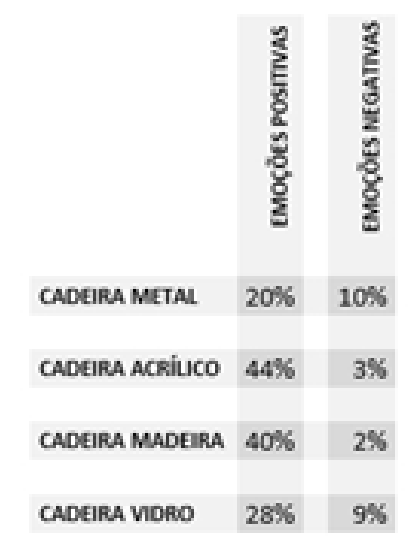

Figura 7 - Distribuição das emoções de acordo com a cadeira avaliada.

Fonte: Elaborado pelo autor, com base na pesquisa realizada.

A cadeira com maiores emoções positivas foi a cadeira de acrílico, seguida pela cadeira de madeira. As cadeiras de metal e vidro foram respectivamente as que receberam mais indicações negativas. Como o preenchimento não implicava na obrigatoriedade em indicar todas as emoções apresentadas na escala circular, a soma das opiniões referentes às emoções positivas e negativas não precisa representar numericamente $100 \%$, pois elas não aconteceram a todos os indivíduos de forma similar. O modelo utilizado com preenchimento dos dados da autoavaliação da cadeira de metal é apresentado na figura 8 com caráter ilustrativo.

Cadeira 1:
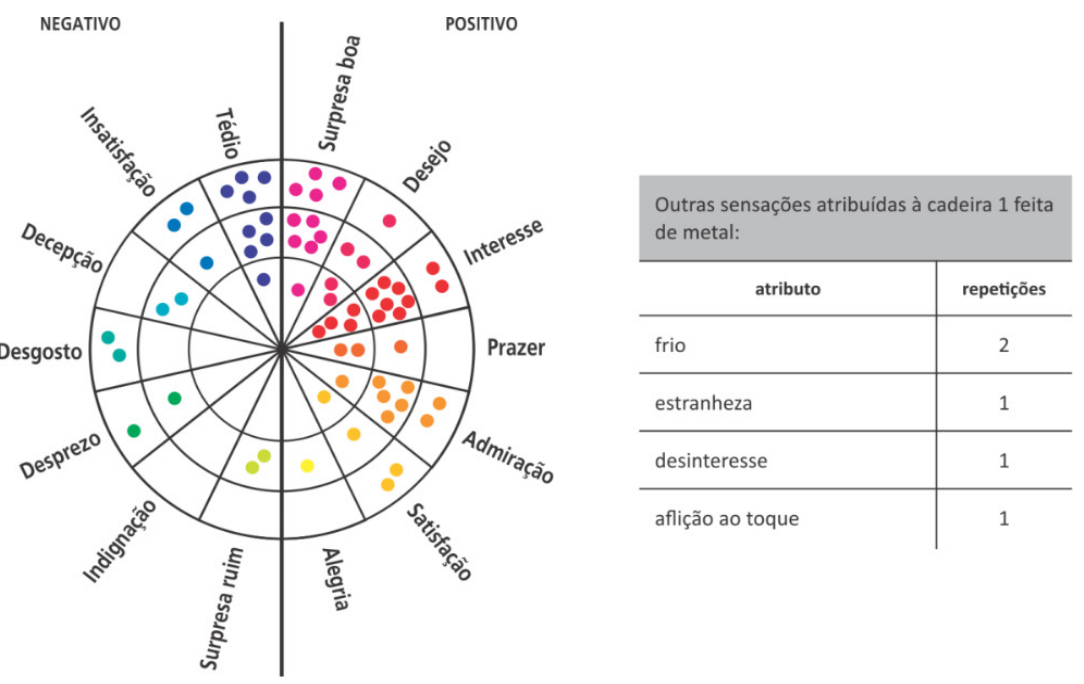

Figura 8 - Resultado da autoavaliação emocional.

Fonte: Elaborado pelo autor, com base na pesquisa realizada.

Além das emoções do círculo de emoções os usuários poderiam indicar outras sensações que sentiam durante a interação e que julgavam ausentes na escala. Em relação a cadeira de metal foram indicadas as sensação de frio, estranheza, desinteresse, aflição ao toque. Quanto a cadeira de acrílico foram relatados bom gosto e curiosidade. A cadeira de madeira instigou indiferença e curiosidade. Já a cadeira de vidro refletiu medo, receio, desconforto, perigo, intranquilidade (frágil), desconfiança e estranheza/inquietação, todos valores considerando negativos em relação a uma cadeira. 


\subsection{Terceiro Momento de Avaliação}

No terceiro momento, os usuários realizavam a avaliação das cadeiras reais e novamente escolhiam a mais e menos preferida após interação, conforme figura 9. Foi dada a orientação para que os usuários tocassem, levantassem e sentassem nas cadeiras.
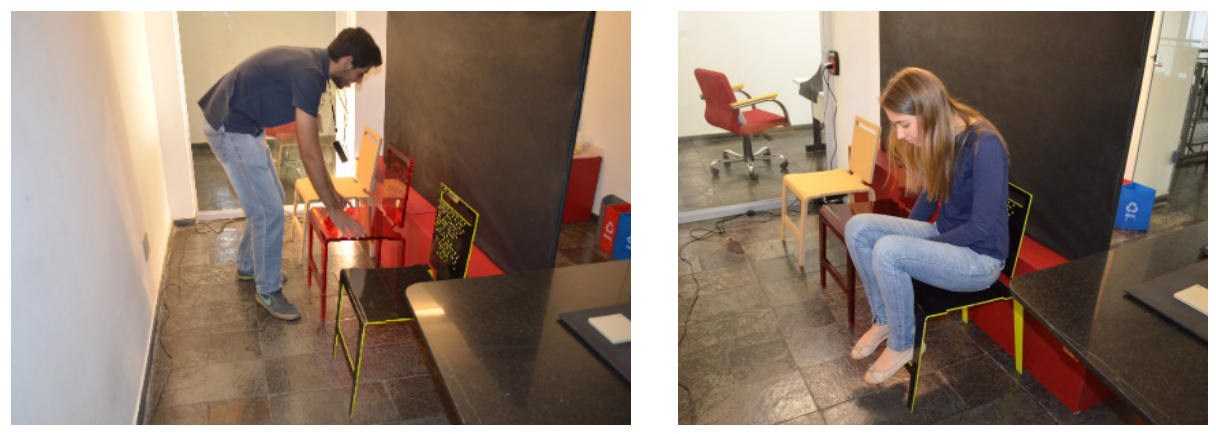

Figura 9 - Momento de interação com as cadeiras.

Fonte: Elaborado pelo autor, com base na pesquisa realizada.

Após interação com as cadeiras, os usuários foram avaliados quanto a sua preferência inicial quando viram as imagens das cadeiras. A intenção foi examinar se, após interação com o produto real, alguma preferência tinha mudado e consequentemente, a escolha feita anteriormente.

Os dados obtidos indicaram que ouve mudança no julgamento após a interação: a cadeira de metal teve diminuição de rejeição de $3 \%$ após contato com o produto; a cadeira de acrílico aumentou em $10 \%$ sua aceitação; a de madeira apresentou diminuição de sua aceitação de $6 \%$; já a cadeira de vidro indicou diminuição de $4 \%$ em sua aceitação e aumento de $3 \%$ de rejeição.

$O$ teste 3 permitiu identificar o perfil subjetivo do material representado por suas características intangíveis, ou seja, os significados atribuídos e as emoções evocadas, que não podem ser puramente identificadas com valores numéricos ou quantificadas.

\section{CONSIDERAÇÕES FINAIS}

Os estudos apresentaram-se como importante meio para conhecimento sobre materiais, produtos e usuários. O conhecimento dos atributos mais valorizados por um grupo de indivíduos permite a construção de um mapa semântico acerca dos materiais, comprovando se suas características técnicas correspondem com a forma como são percebidos pelas pessoas.

A avaliação de materiais, quando aplicados em produtos, exige mais esforço do aparelho cognitivo do indivíduo se comparado à análise de amostras de materiais sem o contexto do produto. Comprovando estudos de Rouvray (2006), o nível de interação ou informação sobre o que é avaliado, interfere na percepção dos indivíduos e nas suas escolhas. Foi possível comprovar também a afirmativa de Ashby e Johnson (2011) que "o produto incorpora parte das propriedades de seus materiais", pois houve reflexo das características deles no julgamento das cadeiras, já que todas eram similares em formato. A personalidade do material influencia nas escolhas individuais. Em alguns casos, os materiais podem transmitir interpretações distorcidas quanto aos aspectos de sustentabilidade, ecologia, durabilidade entre outros. 
A escala de autoavaliação subjetiva teve sua eficiência comprovada assim como descrito por Desmet (2004) e Dias (2009), fornecendo parâmetros de julgamento quanto à intensidade dos atributos sentidos, bem como permitindo classificá-los com valores negativos e positivos. Configura-se, portanto, como uma importante ferramenta de avaliação subjetiva entre materiais, produtos e usuários.

Através das escalas do modelo proposto, foi possível conhecer o comportamento dos indivíduos em relação às cadeiras e seus materiais, compreender que as pessoas repetem padrões preestabelecidos, construídos através de experiências anteriores e que são por sua vez comuns à grande parte das pessoas. Caso não fosse assim, diferentes perfis de usuários não apresentariam possuir um mesmo julgamento em relação a determinado material.

As cadeiras mostraram-se bons objetos de estudo, uma vez que são produtos simples, de uso intuitivo e autoexplicativo, conhecidos e presentes nas casas das pessoas e que, dentro da indústria de mobiliário, mostram-se de relativa significância pelo grande volume de vendas que representam.

\section{REFERÊNCIAS}

ABREU, Aline; CÂNDIDO, G. Ataíde; TEIXEIRA, Joselena de A.. A utilização dos materiais no design e a competitividade da indústria moveleira da Região Metropolitana de Curitiba: um estudo de caso. Produção. São Paulo. v. 11, n. 1, p. 17-30, 2001.

ALMEIDA JR, G. Avaliação dos aspectos subjetivos relacionados aos materiais: proposta de método de mensuração aplicado ao setor moveleiro. 2013. $184 \mathrm{f}$. Dissertação (Mestrado em Design) - Escola de Design, Universidade do Estado de Minas Gerais, UEMG, Belo Horizonte,2013.

ASHBY, Mike F.; JOHNSON, Kara. Materiais e design: arte e ciência da seleção de materiais no design de produto. São Paulo: Elsevier, 2011.

DESMET, P. M. A. A multilayered model of product emotions. The Design Journal, v. 6, n. 2, p. 04-13, 2004.

DIAS, M.R.A.C. Percepção dos materiais pelos usuários: modelo de avaliação Permatus. Florianópolis: UFSC, 2009. 352 p. (Doutorado em Engenharia e Gestão do Conhecimento), UFSC, Florianópolis, 2009.

GALI, Vera. Mobiliário brasileiro: a cadeira no Brasil. São Paulo: Empresa das Artes, 1988.

JORDAN, P. W. Designing pleasurable products: an introduction to the new human factors. London: Taylor \& Francis, 2002.

MANZINI, Ezio. A matéria da invenção. Lisboa: Centro Português de Design, 1993.

MINIM, Valéria P. R. Análise sensorial: estudos com consumidores. 2.ed. Viçosa: Editora UFV, 2010.

NORMAN, D. A. El diseño emocional: por qué nos gustan (o no) los objetos cotidianos. Barcelona, Ediciones Paidós Ibérica, 2005.

ROUVRAY, Alexandre de. Integration des preferences emotionnelles et sensorielles dans la conception de produits d' amaeublent. 2006. Tese (Doutorado). L'École Nationale Supériere d' Arts et Métiers, Paris, 2006. 